\title{
The Study of Inflow Improvement in Spark Engines by Using New Concepts of Air Filters
}

\author{
Sorin Rațiu and Corneliu Birtok-Băneasă
}

Additional information is available at the end of the chapter

http://dx.doi.org/10.5772/48137

\section{Introduction}

The piston internal combustion engine is a thermal engine that converts the chemical energy of the engine fluid fuel into mechanical energy. Engine fluid developments are achieved by means of a piston. The alternative movement of the piston inside a cylinder becomes rotating movement due to the crank gear.

For an internal combustion engine, the gas changing process encloses the intake and exhaust, which condition each other. The intake process is the process during which fresh fluid (air) enters the engine cylinders. The intake (or filling) determines the amount of fresh fluid retained in the cylinder after closing the last filling body and thus the mechanical energy developed during relaxation. The exhaust determines the purification degree of the cylinder with a view to a subsequent fill. In other words, the bigger the amount of fresh fluid (respectively air) retained into the engine cylinders, the higher the engine performance. The large amount of air in the engine cylinders means high pressure and low temperature on the inlet. This is the origin of the idea for this study which seeks ways to maximize, as much as possible, the amount of air introduced into the engine cylinders (by increasing pressure and decreasing temperature into cylinders), during an operating cycle, the costs for this goal being minimal.

Cylinder filling can be normal or forced (supercharging).

Normal filling, or normal inlet, typical of only 4-stroke engines, is achieved due to the piston's movement in the cylinder, in the sense of volume increase. Volume growth is recorded in the intake stroke, the fresh fluid with atmospheric pressure on the inlet.

Forced filling is achieved when the inlet pressure is greater than atmospheric pressure, indispensable in the 2-stroke engine without gas exchange bound drives. Forced filling can be achieved by supercharging when special equipment prepares the fresh fluid to enter the engine inlet at a pressure greater than the atmospheric one. 
The cylinder filling process is strongly influenced by gas-dynamic losses on the engine intake route. There are two kinds of losses:

- Thermal losses due to heating the fluid through the inlet route walls, thus the final temperature being $\mathrm{T}+\Delta \mathrm{T}$, the temperature increase resulting in diminishing density and hence the filling penalty.

- Pressure losses caused by the existence of hydraulic resistances on the intake route and fluid friction with the pipe walls. These can be quantified according to the well-known formula [1]:

$$
\Delta p=\xi \cdot \rho \cdot \frac{w^{2}}{2}
$$

where $\xi$ is the pressure loss coefficient, $\mathrm{w}$ is the flow speed of the fresh fluid and $\rho$ is its density.

Due to these losses, the amount of fresh charge retained in the engine cylinders, while providing information on the filling conditions, cannot serve as a comparison standard for different engines, but only for the same engine (the size of the losses mentioned above differs from one engine to another). This is why we introduce the notion of filling degree, or filling coefficient, or filling efficiency as a criterion for assessing filling perfection [1]:

$$
\eta_{v}=\frac{C}{C_{0}}
$$

where $C$ is the amount of fresh fluid actually retained in the cylinder, and $C_{0}$ is the amount of fresh fluid that could be retained in the cylinder, under the state conditions of the engine inlet, i.e. without taking into account the losses mentioned above.

Proper filtering of the air that enters the internal combustion engine cylinder is essential to extend its operation. Preventing the intake of various impurities along with atmosphere air significantly reduces the wear and tear of engine parts in relative movement.

Unfortunately, besides the function of filtering air drawn from the atmosphere, the air filter - as a distinct part in engine composition - is a significant gas-dynamic resistance interposed on the suction route. If it is not cleaned regularly and the vehicle is driven frequently in dusty areas, the suction pressure $p_{a}$ is reduced consistently and the filling efficiency $\eta_{v}$ suffers penalties [1].

The air filters for filtrating sucked air, needed for the running of internal combustion engines, are made in several variants that differ according to the filtration principle:

- $\quad$ filters with filter element;

- filters by inertia;

- combined filters.

These variants have the following disadvantages:

- the existence of the filter element inside the case marks increased gas-dynamic resistance on the absorbed air (resulting in insufficient absorption phenomenon); 
- the storage of dirt inside the filter interferes with the self-cleaning property of the filter element;

- the inability to view the filter element without prior removal of the filter to verify its impurity loading degree;

- the inability of the air filter to considerably increase the speed of the absorbed air;

- the inability of the air filter to pre-cool the air drawn into it;

- the inability of the air filter to create a slight boost while driving.

Air filtration is characterized by the following parameters:

1. average retention efficiency - measure of the filter's ability to capture dust and other impurities from the filtered air, expressed in [\%];

2. filter class - the filter material's ability to retain particles of minimum specified size;

Composition of dust particles in the air, for example see [2]:

Airborne dust is extremely variable both as component material and particle size, depending on geographical area and climate. In general, airborne dust contains $\mathrm{SiO}_{2}, \mathrm{CaO}_{2}$, $\mathrm{MgO}, \mathrm{Fe}_{2} \mathrm{O}_{3}, \mathrm{Al}_{2} \mathrm{O}_{3}$, alkaline material, organic material, soot, debris and smoke. Most dangerous for the engine are quartz particles (sand), quartz being one of the strongest abrasives. Organic substances are harmless to the engine.

The density of dust in the air is between $0.0002 \mathrm{~g} / \mathrm{m}^{3}$ in winter and 3-4 g/m $/ \mathrm{m}^{3}$ in summer, on earth roads from 0.5 to $1 \mathrm{~m}$ height above the ground. On paved roads, in summer, dust content in the air is 0.001 to $0.002 \mathrm{~g} / \mathrm{m}^{3}$, i.e. 20 to 30 times higher than in winter; the density variation between the minimum and maximum, i.e. from 0.0002 to $4 \mathrm{~g} / \mathrm{m}^{3}$, is 1 to 20000 . If during daytime you can see only up to 25 to $30 \mathrm{~m}$, there is about $1 \mathrm{~g}$ dust $/ \mathrm{m}^{3}$ of air.

The most dangerous particles are quartz grains exceeding 0,010 $\mathrm{mm}$, quartz being a powerful abrasive which causes wear and tear 2-3 times more than smaller particles. There is no air filter to stop all the dust in the air, meaning one with $100 \%$ filtration efficiency.

\section{Brief history of the evolution of air filters}

At the beginning of the internal combustion engine evolution, the air filter's role was limited to the simple function of filtering the air entering the cylinders, air absorption taking place only from the engine compartment, regardless of season. Filter element was made of stainless steel sieves overlaid in 5 to 10 layers. Filter shape, respectively of the filter element, was mostly cylindrical (Figures 1-4) [2].

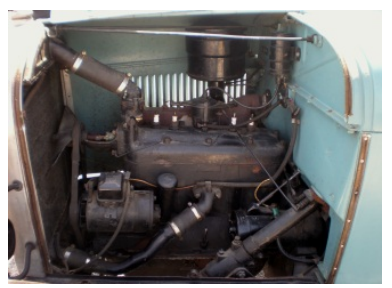

Figure 1. FORD T Model 1928 


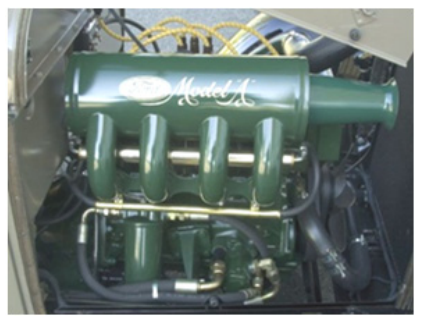

Figure 2. FORD A Model 1929

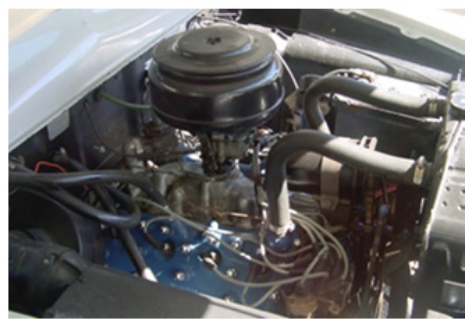

Figure 3. FORD V8 1932

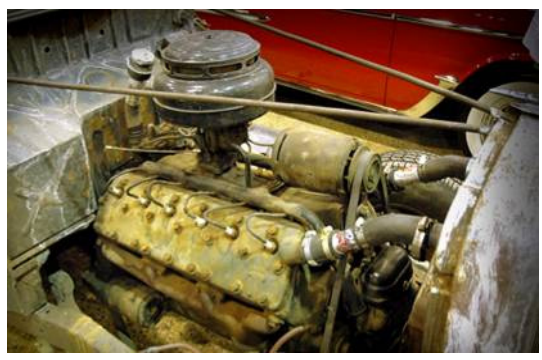

Figure 4. FORD V8 1932

In certain racing engines with carburetors mounted on each cylinder, there is even no air filter, the engine sucking air directly from the engine compartment, without pre-filtering it (Figure 5).

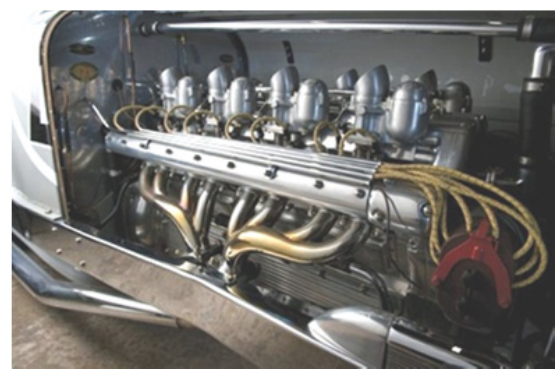

Figure 5. MILLER V16 1931 
The filter element becomes a consumable item, being replaced at road running intervals set by each manufacturer.

After the '40s, differential absorption of air depending on season starts to appear: in summer outside the engine compartment and in winter from the exhaust manifold area (Figures 611) [2].

The filter element known today as microporous or textile cardboard appears much later, in a variety of forms, the most common being the panel (Figure 12).

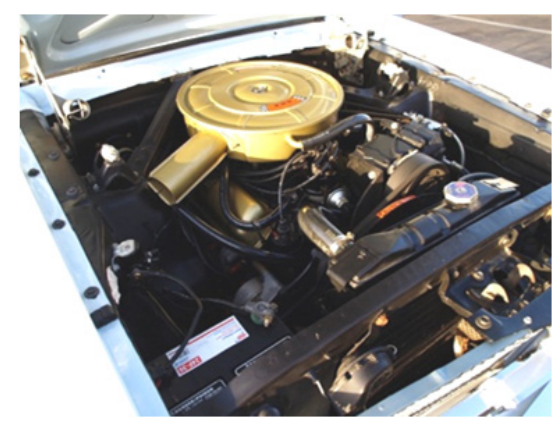

Figure 6. . FORD MUSTANG I 1964

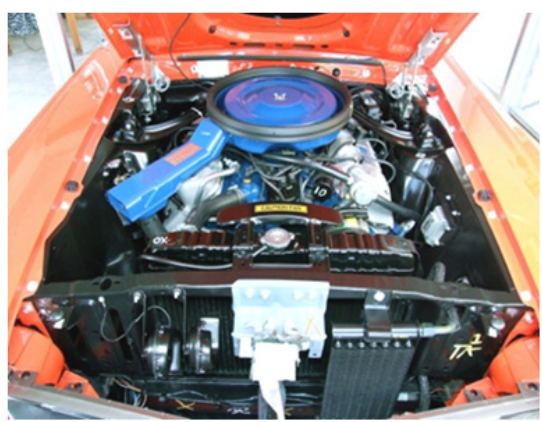

Figure 7. FORD MUSTANG II 1974

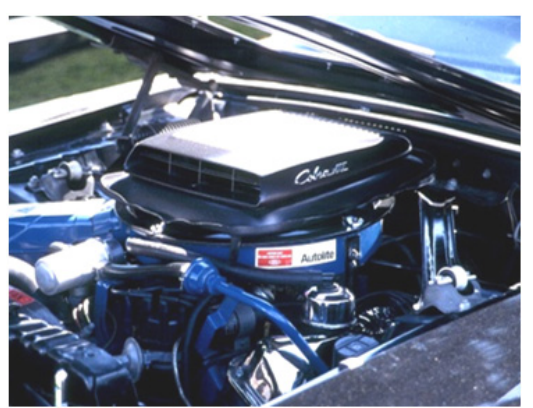

Figure 8. FORD MUSTANG GT 1982 


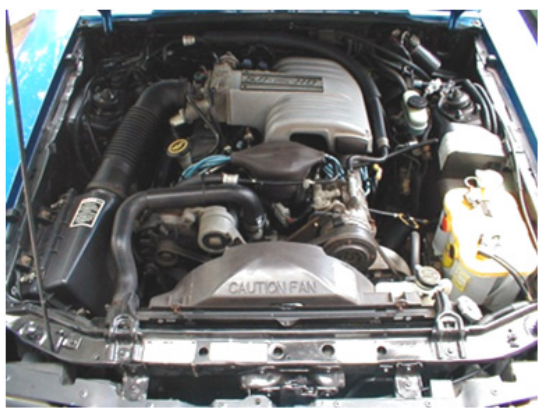

Figure 9. FORD MUSTANG 1994

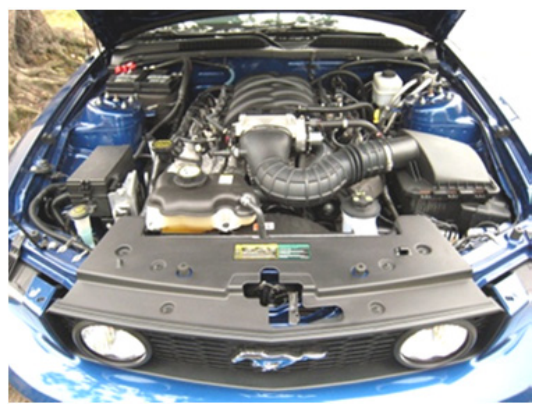

Figure 10. FORD MUSTANG 2001

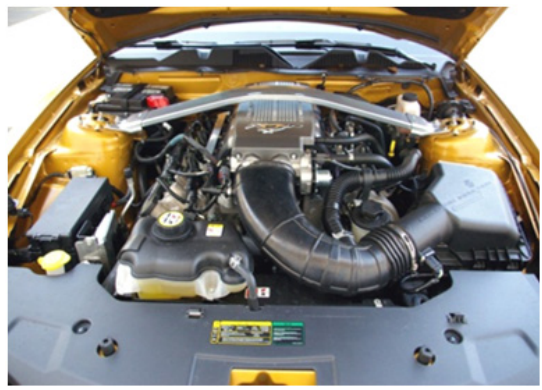

Figure 11. FORD MUSTANG 2005

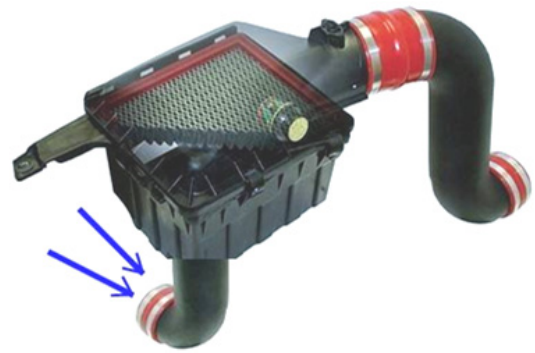

Figure 12. Panel type air filter 


\section{Super absorbing air filters (SAAF) - Own concepts $[2,5]$}

From the outset it should be noted that the concepts proposed by the authors refer exclusively to air filter casing. The filter element is standard, purchased from well-known manufacturers.

The super absorbing or multifunction filters designed by the authors fulfil, besides the main task of filtering the air, the following functions:

- $\quad$ To capture the air;

- To increase the air flow rate of the absorbed air;

- To pre-cool the air;

- To change the airflow direction;

- To increase the filling coefficient or efficiency.

Here follows a classification of the super absorbing filters depending on assembly position, gauge dimensions and air intake function.

\subsection{Super absorbing cylindrical air filter with internal diffuser (SAAFid)}

The internal diffuser has the additional function of accelerating air speed out of the filter. The design geometry provides considerable increase in the coefficient of filling the cylinders with air.

The internal diffuser has variable sizes, depending on engine displacement. The larger the displacement is, the higher the diffuser sizes are, and vice versa.

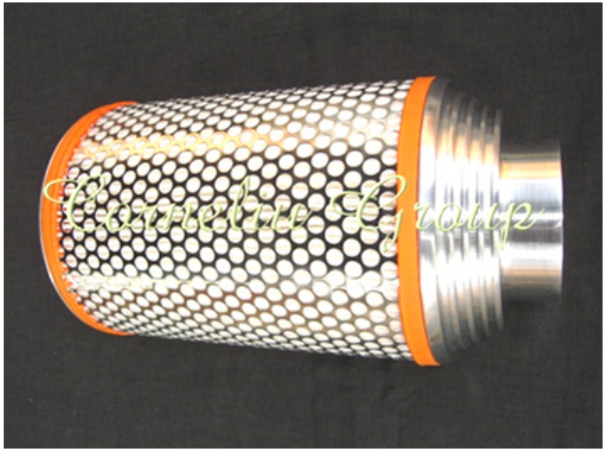

(a)

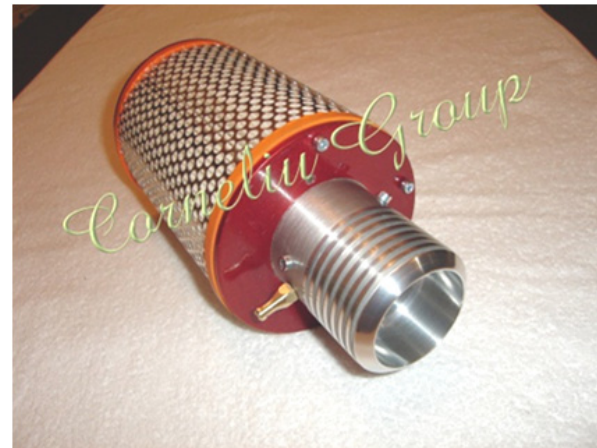

(b)

Figure 13. Super absorbing filter with internal diffuser: $a, b$ - physical models

\subsection{Supliform super absorbing air filter (suSAAF)}

It is mainly based on space-saving, reduced gauge dimensions (flexibility), being useful where the engine compartment is very tight (large capacity engines with supercharging installations). This filter allows, in its turn, function multiplication, namely, besides the main 
function of filtering the air, the filter increases the absorption and intake rate, as well as the speed of the absorbed air, also cooling it. This filter type can be a filter with one filter area and external collector, and a filter with dual filtration area.

The supliform air filter with one filter area consists of an axial external collector of cylindrical-concave shape (in radial section it is an arc), lined with filter element, concentration surfaces and connection cylinder (figure14).

The arc-shaped axial external sensor is radially closed at both ends with two concentration surfaces (crescent shaped) (Figures 14.c).

The filter element is recessed axially between the collector edges and radially between the concentration surfaces.

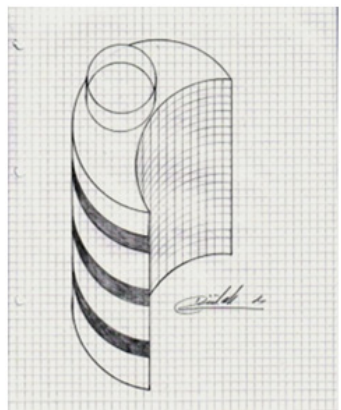

(a)

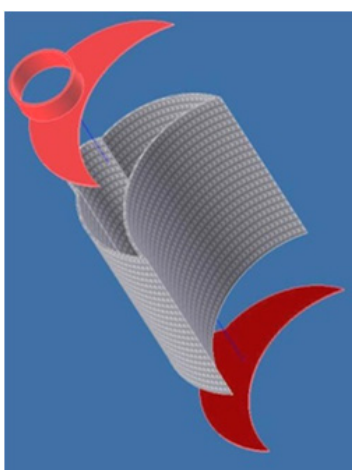

(c)

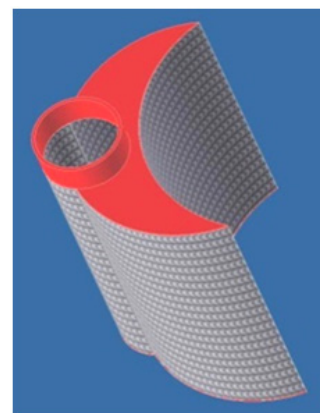

(b)

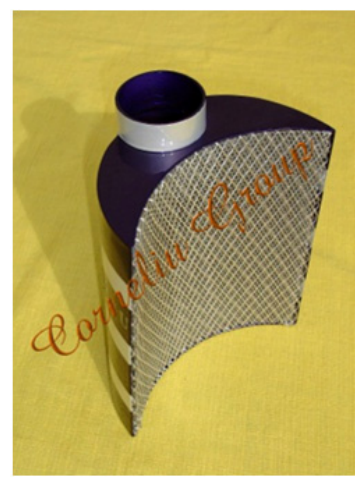

(d)

a - sketch, b - virtual model made in AutoDesk Inventor, c - exploded virtual model, d - physical model

Figure 14. Supliform super absorbing air filter with one filter area and external collector 
On one of the concentration surfaces there is the fitting cylinder (Figure 14.d), which provides connection of the supliform filter to the engine inlet.

The collector, together with the concentration surfaces, captures radially and directs axially the air into the fitting cylinder (towards filter exit).

Due to its geometric shape, the collector ensures the minimum gas-dynamic resistance and creates a slight boost which increases proportionally with the speed of the vehicle, increasing considerably the amount of air absorbed and thus the filling coefficient of the engine.

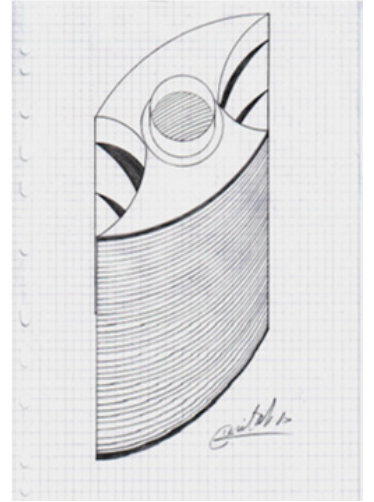

(a)

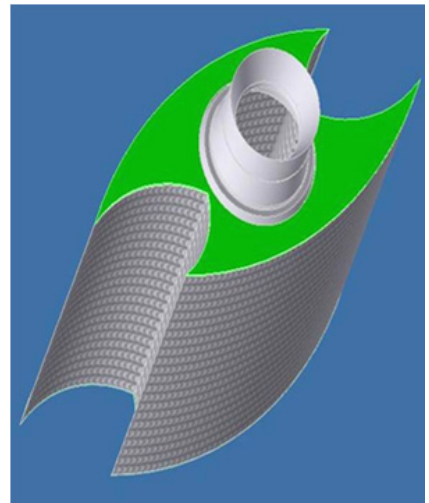

(b)

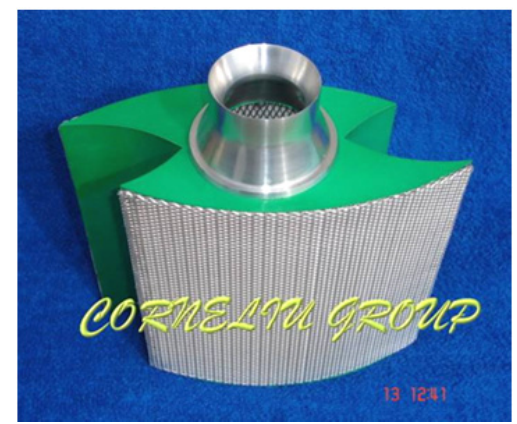

(c)

a - sketch, b - virtual model made in AutoDesk Inventor, c - physical model

Figure 15. Supliform super absorbing air filter with dual filtration area

The filter element has a concave semi-cylindrical shape (Figure 14.d) and defines the area located between the collector edges and concentration surfaces. It is made of micron cardboard placed so that it forms the lateral area of the filter element (in radial section the micron cardboard has a VV shape). The cardboard provides a fine filter (microns) and is 
covered on the outside with a millimeter sieve, which allows coarse air filtering (millimeter). The micrometer cardboard and millimeter sieve are rigid (fixed) at both open ends with silicone semi-rings for better alignment and ideal tightness relative to the sensor edges and concentration surfaces.

The supliform air filter is mounted radially to the geometric axis of the vehicle (perpendicular on travel direction) for proper intake and absorption performance (Figure 16).

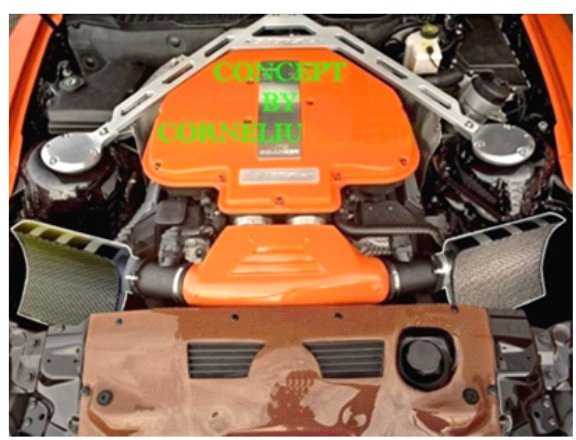

Figure 16. Mounting supliform air filter on engine

\subsection{Super absorbing air filter with wide filtration range (SAAFwr)}

This type of filter is made up of a front diffuser and a side surface with guiding cells, allowing the capture of both front and side air, thus increasing the surface of air penetration into the filter.

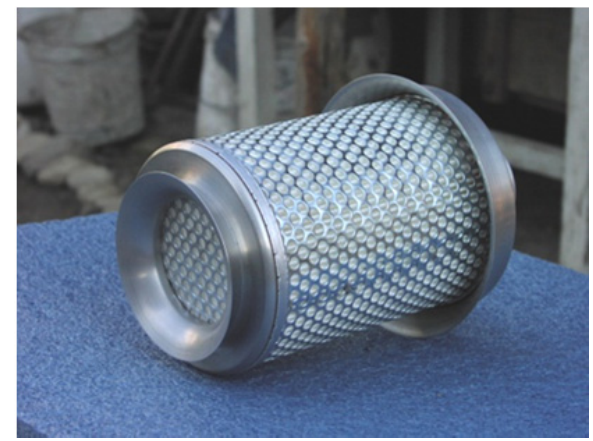

Figure 17. Super absorbing air filter with wide filtration range

\section{Dynamic air transfer device (DATD) [2,5]}

During operation of internal combustion engines fitted on motor vehicles in summer, there can be noted two shortcomings of the super absorbing filters, leading to their poor performance: 
- insufficient air suction effect due to their installation in the engine compartment, area where the airflow is turbulent, the airflow around the filter not being laminar but turbulent, and the volumetric efficiency suffering penalties;

- increase in the absorbed air temperature due to their installation in the engine compartment, area which is subject to thermal radiation (of the cooling radiator and exhaust manifold). The overheating of the fresh fluid increases engine temperature, the appearance of detonation combustion and engine power reduction.

Figure 18 presents the most disadvantageous fitting solutions in terms of exposure to thermal radiation and eddy currents.

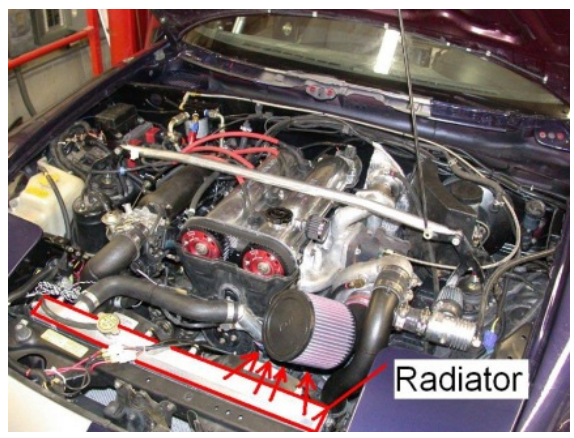

(a)

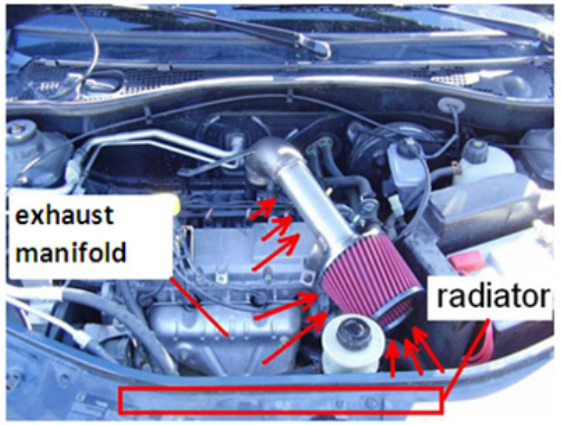

(b)

Figure 18. Assemblies that lead to direct exposure of the filters

It was tried to use a separator compartment for the air filter (Figure 19). But the separator compartment does not provide ideal insulation against the engine compartment, allowing thermal radiation to enter the air filter. Due to its design, turbulent air currents are created inside the separator compartment.

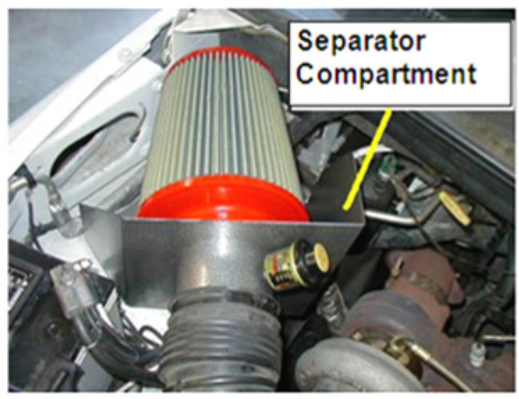

(a)

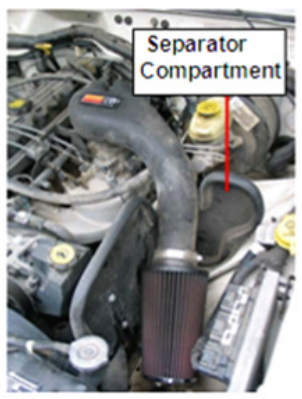

(b)

Figure 19. Installing filters in separator compartments

Moreover, the extension of the intake route outside the engine compartment is also practised. The example is given by mounting the air filter in the front bumper of a Honda 
Civic R Type. At the same time, the incorporation of the air filter in aluminum or carbon cage is also practised.

By using the above solutions, the disadvantages mentioned are partially eliminated, but there is significant pressure loss due to extension of the intake route and existence of casting. Suction pressure is reduced consistently. On average, the intake route distances increase by over $500 \mathrm{~mm}$, leading to increased drag created by additional friction arising from contact with the intake route wall.

Considering the above drawbacks, an efficient intake device was designed for internal combustion engines, called dynamic air transfer device (DATD) (Figure 20). It helps improve air circulation to the filter air through the engine compartment.

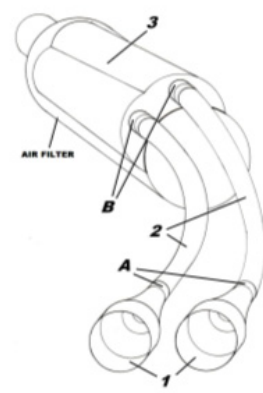

(a)

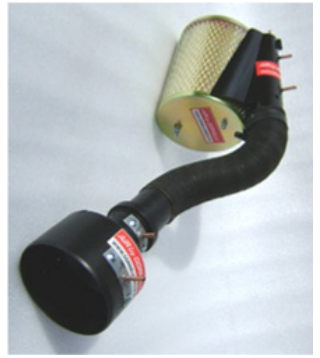

(b)

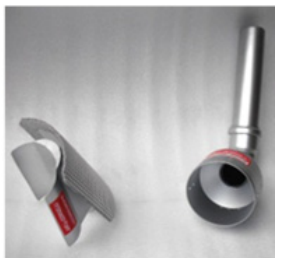

(c)

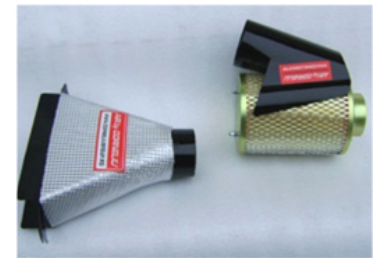

(d)

a - design scheme: 1 - external collector diffuser, 2 - pipe connection, 3 - axial external collector,

A, B - connecting surfaces; $b$ - real overview; c - axial external collector and external collector diffuser - overview; $\mathrm{d}$ - different types of axial external collector and external collector diffuser.

Figure 20. Dynamic air transfer device (DATD)

The novelty consists in mounting external collector diffusers longitudinally with the vehicle axis, in the front area (in front of the radiator area or in the front bumper). They drive the air trapped outside the engine compartment, through the pipe connection, to the axial external collector, where the transfer to the air filter takes place.

The dynamic air transfer device consists of:

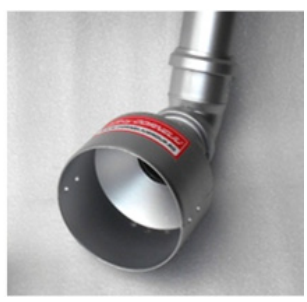

(a)

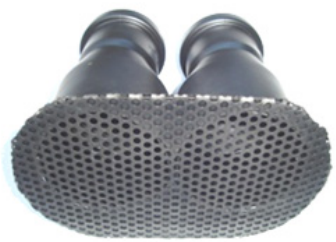

(b)

Figure 21. External collector diffusers - physical models 
1. External collector diffusers (one or more), whose role is to capture and accelerate air velocity (Figure 21).

2. Pipe connection, which connect the external collector diffusers and axial external collector (Figure 22).

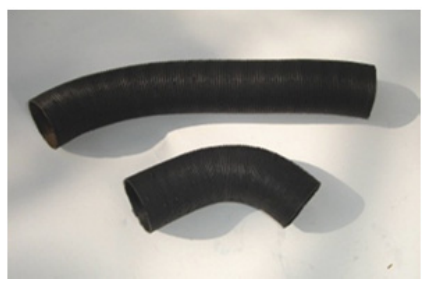

Figure 22. Pipe connection

3. The axial external collector (mono or bi-route), Figure 23, is mounted on the super absorbing air filter oriented to the high heat radiation areas (exhaust manifold, radiator, engine). It takes at least $30 \%$ of the lateral filter area, being at a well-determined distance away from the filter (between 3 and $8 \mathrm{~mm}$ ). Its role is to transfer the air flow in the filter, flow divided into two components: one that actually enters the filter, the actual flow being admitted into the engine cylinders and one that surrounds the lateral surface of the filter, leading to keeping a relatively low filter temperature.

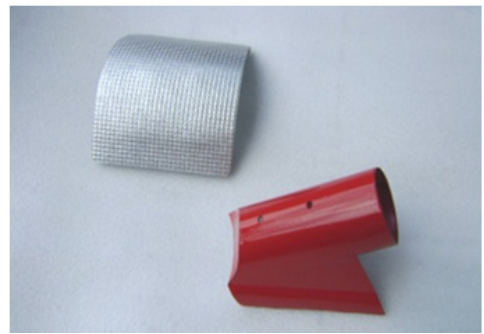

(a)

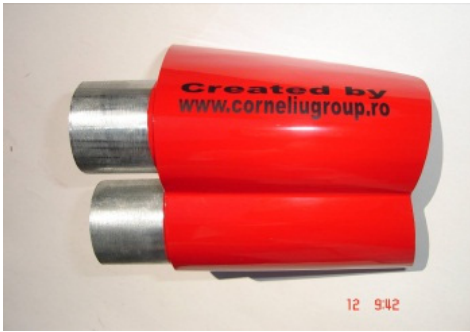

(b)

$\mathrm{a}$ - mono-route, $\mathrm{b}$ - bi-route

Figure 23. Axial external collector

While driving the vehicle, the air is taken over by the external collector diffusers which enhance its speed, concentrate and convey it through the pipe connection to the axial external collector that transfers it to the super absorbing air filter.

The air stream transferred (brought) from outside the engine compartment has laminar focused flow. Speed increases (task performed by the external collector diffusers), and at the same time the air flow temperature decreases significantly. Because of its design geometry, the axial external sensor ensures good transfer and dispersion of the air on the side area of the super absorbing air filter. The amount of transfered air increases proportionally with the speed of the vehicle. 


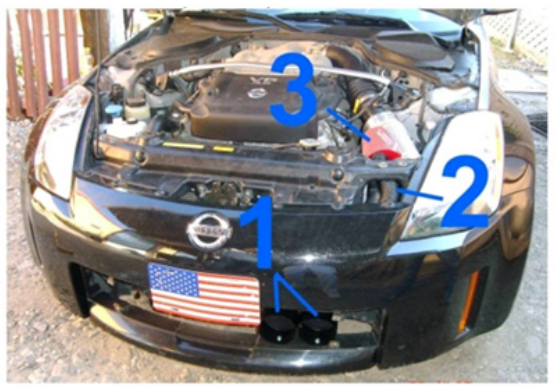

(a)
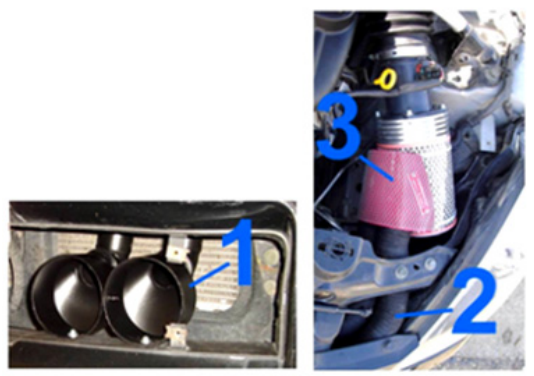

(b)

Figure 24. a - DATD mounted on the engine; $b$ - component parts: 1 - external collector diffusers, 2 pipe connection, 3 - bi-route axial external collector

Advantages of DATD:

- the air transfer to the filter has laminar focused flow;

- the low air temperature provides improved filling efficiency;

- a slight boost is created increasing proportionally with the speed of the vehicle;

- $\quad$ the combustion process is improved;

- the tendency is toward dynamic inlet;

- it allows shortening the distance between the filter and the intake manifold.

Depending on engine capacity, one should use one or two external collector diffusers and an axial external collector in one or two transfer routes with varying sizes.

\subsection{Experimented DATD}

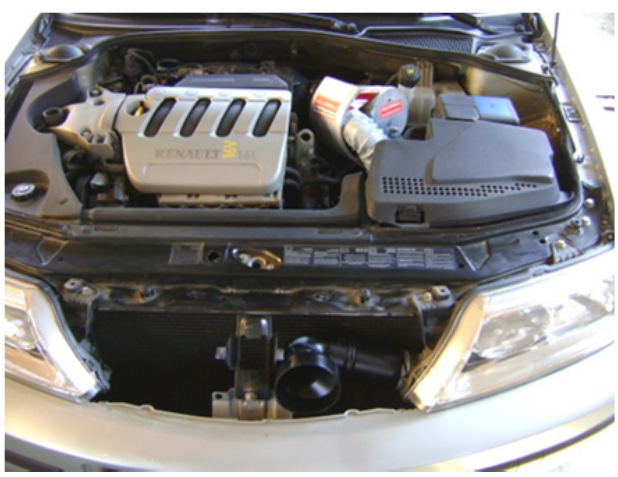

Figure 25. DATD mounted on Renault LAGUNA $1.616 \mathrm{~V}$

Differential pressure measurements were made both in the presence of the axial external collector of the DATD, and in its absence, in the suction area of the air filter, on different speed ranges. Data were taken while driving in real traffic at different speeds of the vehicle. 


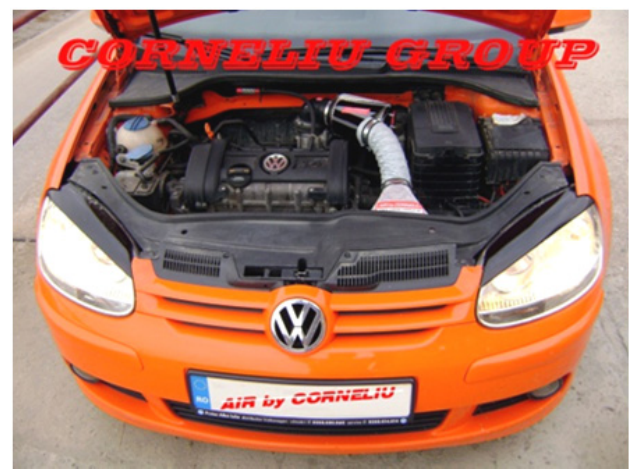

Figure 26. DATD mounted WV Golf 5, $1.416 \mathrm{v}$

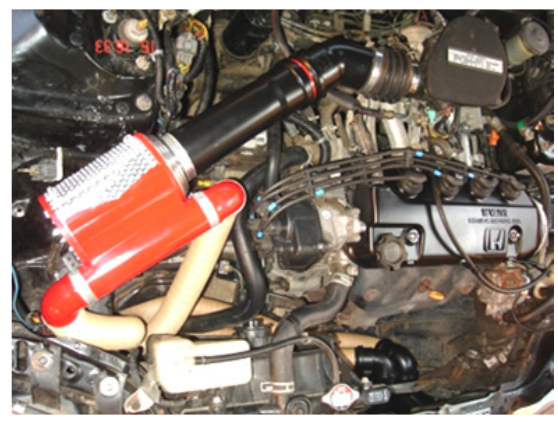

Figure 27. DATD, bi-route mounted on Honda Civic, 1.6

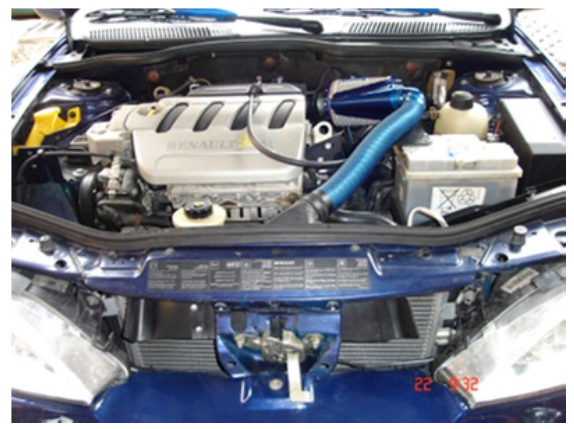

Figure 28. DATD, mounted on Renault Megane Coupe

For measurements in the transfer area of the axial external collector - air filter, the pressure intake port was oriented axially to the airflow direction.

For measurements without DATD, in the suction area of the air filter, the pressure intake port is directed axially to the air absorption direction.

One can notice a higher air capture and transfer effect obtained by DATD, in comparison with the simple absorption of the super absorbing air filter. This effect is accentuated by 
higher values of the relative air pressure in the capture area obtained by DATD, in comparison with the relative pressure values in the absorption area of the air filter in the absence of DATD. This is particularly beneficial, especially for non-supercharged engine intake (normal inlet), the amount of air admitted into the engine cylinders being directly proportional to the intake pressure.

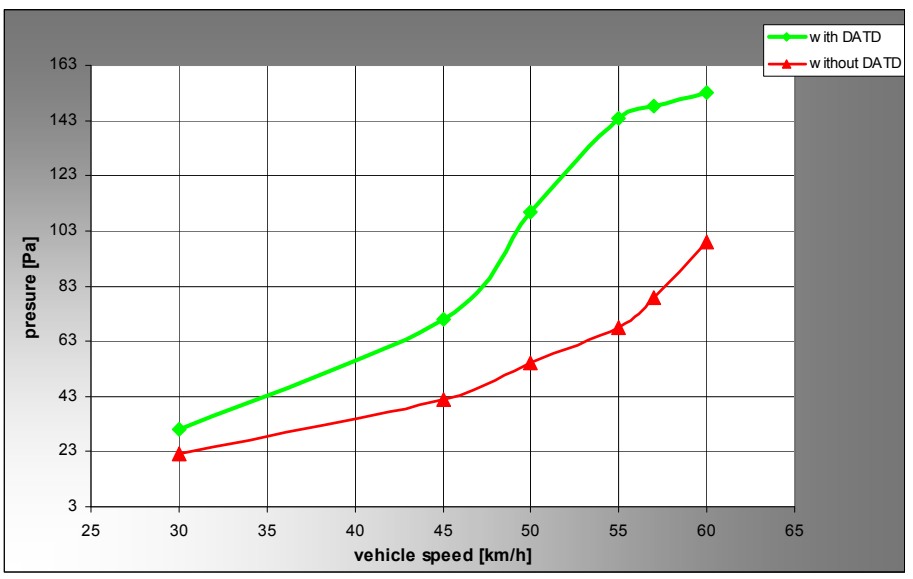

Figure 29. Comparative graph of the relative air pressure fields in the suction area of the air filter, in the presence and respectively absence of DATD

Here are some comparative measurements of the temperatures of the outer surfaces of the original classic air filter (OAF) and super absorbing air filters with DATD (SAAF+DATD) in real traffic conditions.

From the graphs above it can be seen that the temperatures of the outer surfaces of the super absorbing filters, in combination with the dynamic air transfer device (SAAF+DATD), are much lower than the ones corresponding to the outer surfaces of the original air filters (OAF). Consequently, the use of super absorbing air filters together with DATD leads to less acute air heating on the intake route and therefore improvement of the filling coefficient.

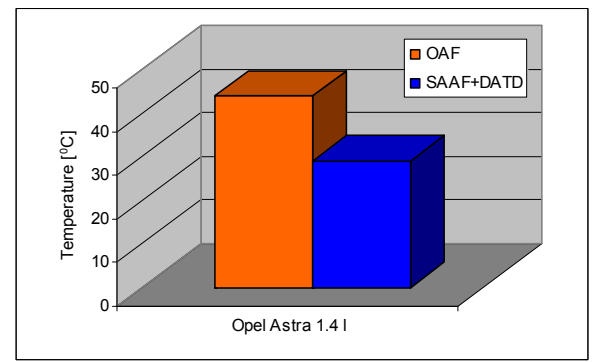

Figure 30. Temperatures of the outer surfaces of the OAF and SAAF+DATD for Opela Astra 1.4i 


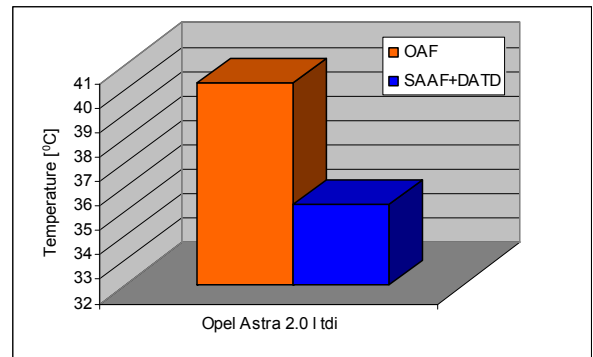

Figure 31. Temperatures of the outer surfaces of the OAF and SAAF+DATD for Opela Astra 2.0tdi

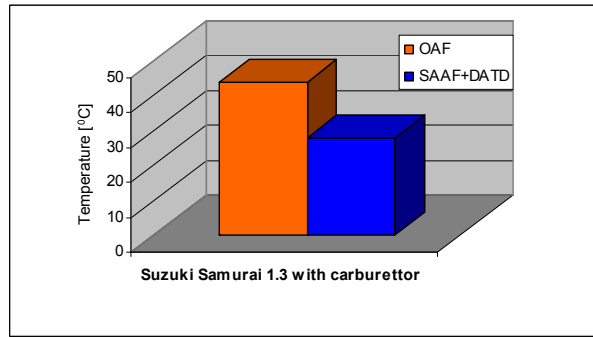

Figure 32. Temperatures of the outer surfaces of the OAF and SAAF+DATD for Suzuki Samurai

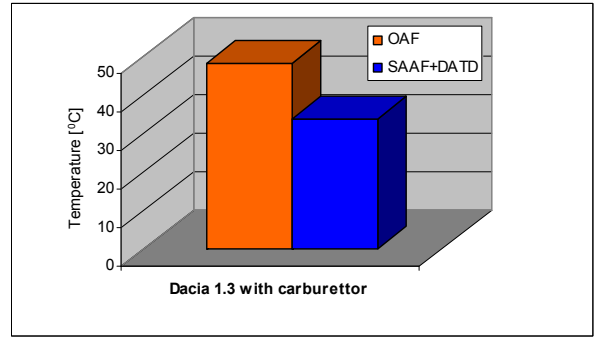

Figure 33. Temperatures of the outer surfaces of the OAF and SAAF+DATD for Dacia 1.3

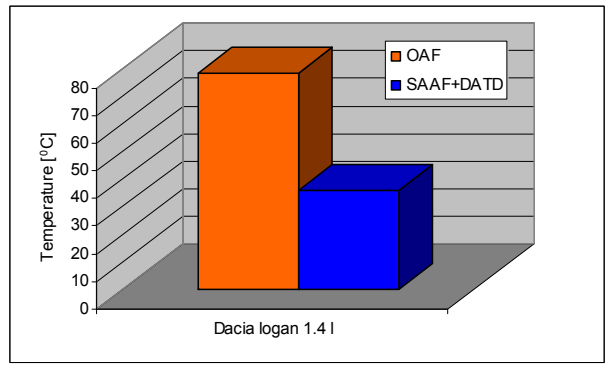

Figure 34. Temperatures of the outer surfaces of the OAF and SAAF+DATD for Dacia Logan 1.4i 


\section{Integrated deflector (ID) for attenuation of thermal radiation coming from the cooling radiator [2]}

The thermal radiation and warm air from the engine cooling radiator extra heat the air filter and intake manifold. The absorbed air is also heated thus decreasing its density, the engine performance diminishing especially in hot weather. The air filter and intake manifold temperatures vary, in this case, between 60 and $85^{\circ} \mathrm{C}$, depending on the car speed.

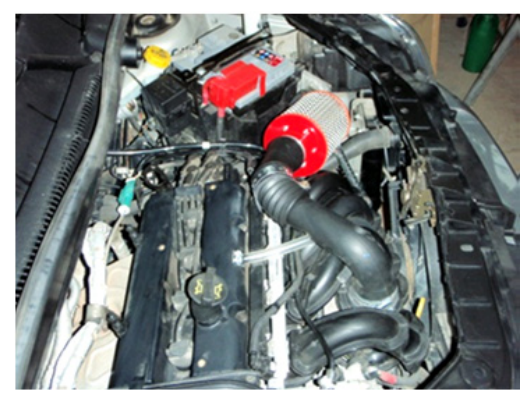

Figure 35. Illustration of thermal radiation orientation towards the air filter

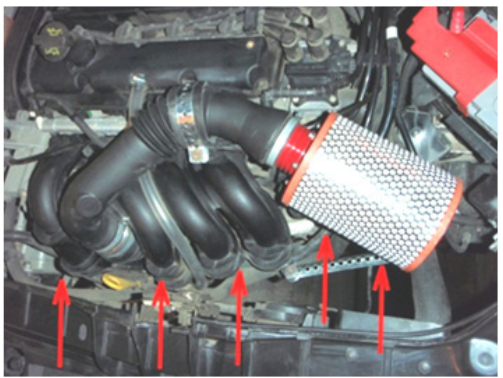

Figure 36. Filter assembly without the cooling radiator's integrated deflector

The cooling radiator's integrated deflector is designed to reduce these shortcomings, being mounted behind the radiator fan to direct the air flow beneath the inlet level (downwards). The deflector is thermally insulated (Figure 38), the filter and manifold temperatures falling within the range $25 \ldots 37^{\circ} \mathrm{C}$ when the deflector is used.

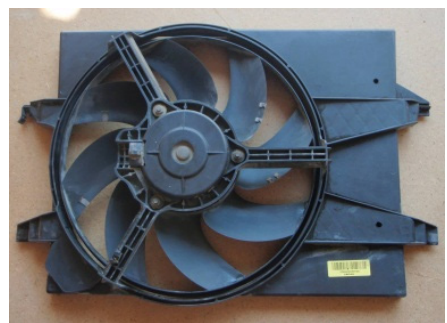

Figure 37. Radiator fan 


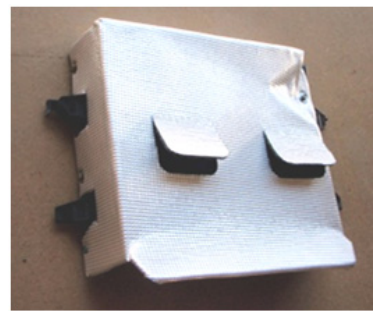

Figure 38. Integrated deflector - physical model

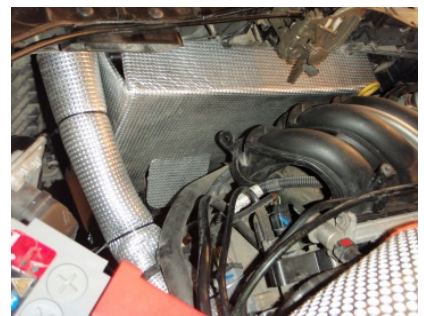

(a)

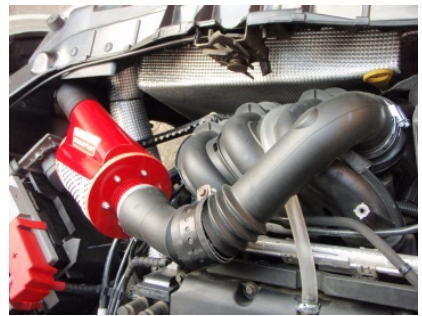

(b)

Figure 39. a,b - Overview of radiator with mounted deflector

As already mentioned, the purpose of the integrated deflector is to direct downward the hot airflow passing through the engine cooling radiator (Fig. 40, b).

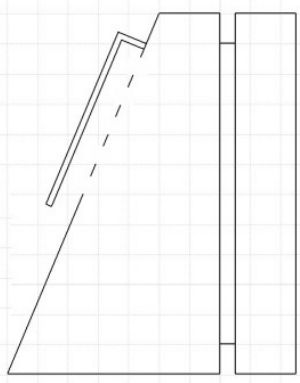

(a)

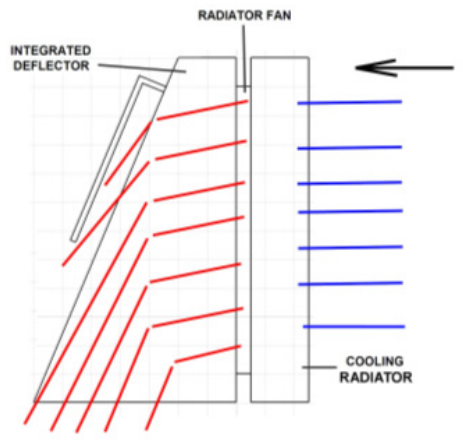

(b)

Figure 40. Integrated deflector: a - sketch, b - operation principle

The technical problem solved consists in protecting the intake manifold and air filter from the heat radiation coming from the engine cooling radiator.

By use of the deflector integrated the following advantages are obtained:

- downward direction of the hot airflow coming from the cooling radiator (thermal radiation), outside the engine compartment; 
- maintaining an optimum temperature of the intake manifold and air filter (to avoid overheating them).

The integrated deflector is provided with a deflector wall (Figure 41), which has a rectangular concentration area (2) fixed on the upper end. The concentration trapezoidal surfaces (3) and (4) are fixed on the lateral ends of the deflector wall (1), with the large trapeze end at the bottom. The deflector wall (1) has two or more directional windows (5).

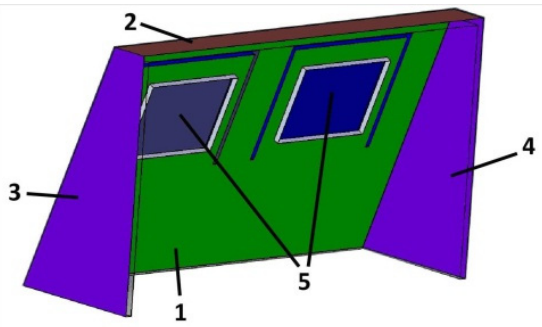

(a)

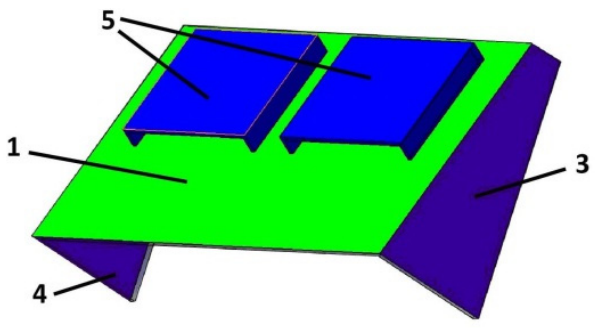

(b)

Figure 41. Integrated deflector - virtual model, made in Autodesk Inventor: 1 - deflector wall, 2 - rectangular concentration area; 3, 4 - trapezoidal concentration surfaces; 5 - directional windows

The bottom surface between bases (3), (4) and the bottom edge of the deflector wall (1) is open (free) to allow the evacuation of most hot airflow coming from the cooling radiator. The directional windows (5) allow additional exhaust of the hot airflow coming from the cooling radiator.

The deflector is not bad for engine cooling, the operating temperature of the coolant remaining within normal operating parameters.

Further experimental measurements are shown for comparative temperatures of intake air in the presence and absence of the deflector. Please note that in summer tests were made on

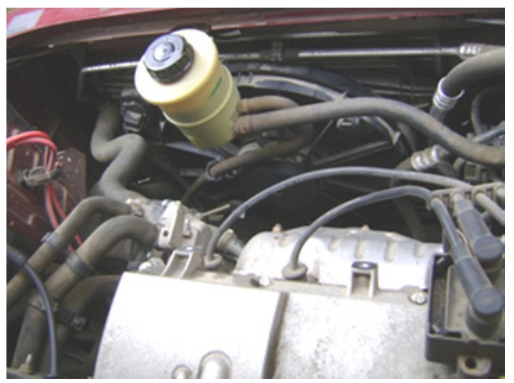

(a)

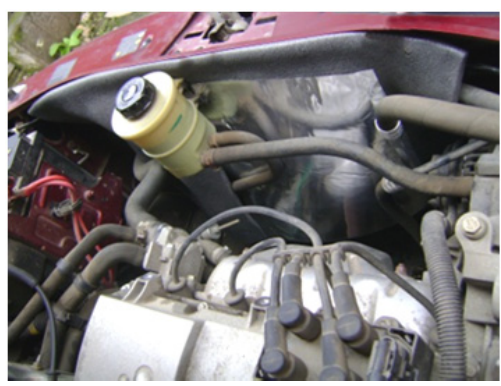

(b)

Figure 42. Overview of engine radiator tested: $\mathrm{a}$ - without integrated deflector, $\mathrm{b}$ - with integrated deflector mounted 
4 different cars, drawing the conclusion that the deflector has no adverse effect on engine cooling, the operating temperature of the coolant remaining within the parameters specified by the manufacturer.

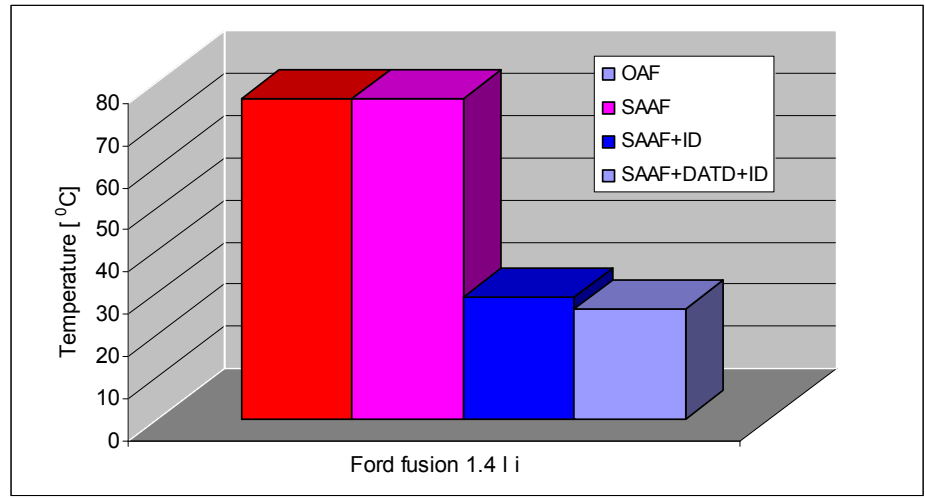

Figure 43. Intake air temperature values in the proximity of the air filter

As illustrated in Figure 45, the intake air temperature values for the original air filter (OAF) and the super absorbing air filter (SAAF) are similar in size and relatively high, leading to low density of the fresh load in the cylinders and thus to reducing the filling efficiency. Conversely, the temperature values recorded in the presence of the super absorbing air filter with integrated deflector (SAAF+ID) and to which the dynamic air transfer device is added $(\mathrm{SAAF}+\mathrm{DADT}+\mathrm{ID})$ are much lower than the previous ones, which favors the improvement of the filling efficiency.

In conclusion, we can say that the dynamic air transfer device together with the integrated heat deflector, lead on the one hand to increasing the fresh fluid intake pressure, and on the other hand to lowering its temperature, both solutions contributing to increasing the filling efficiency $\eta_{v}$ of the engine cylinders.

\section{Experimental laboratory tests}

The purpose of these experiments is to test the concepts of the super absorbing air filters and DATD designed and carried out by the authors, previously presented in detail. Testing was performed on an experimental stand, located in the Laboratory of Internal Combustion Engines of the Faculty of Engineering of Hunedoara, Romania.

The data were processed and compared with those obtained when operation took place the original engine filter provided by the manufacturer. There is clear improvement of pressure on the inlet route, when super absorbing filters and the dynamic air transfer device are installed.

The experimental measurements were based on a stand containing a 4-stroke 4-vertical inline cylinder spark ignition engine, the camshaft in the crankcase, Dacia brand, model 
810.99 , with carburettor, and related equipment, stand which allows setting the pressure field on the engine intake route (Figure 44 ), for example see $[2,3]$.

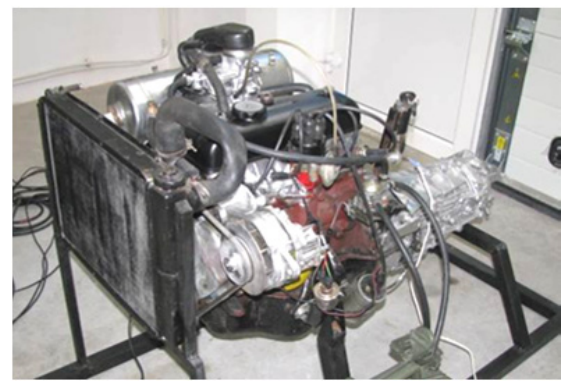

Figure 44. Overview of experimental stand

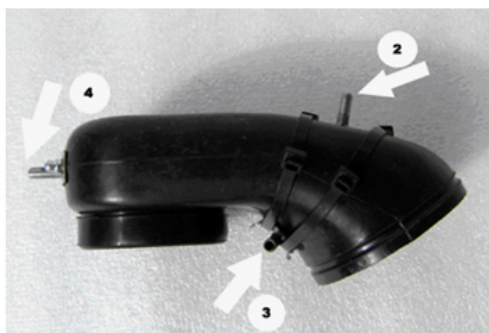

(a)

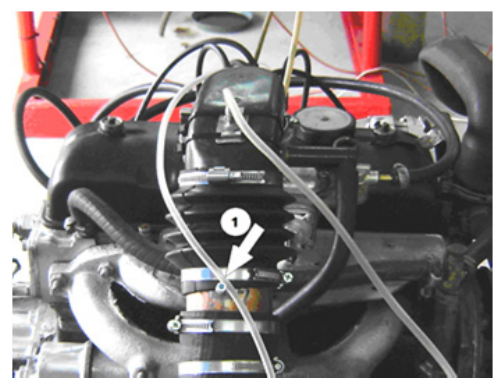

(b)

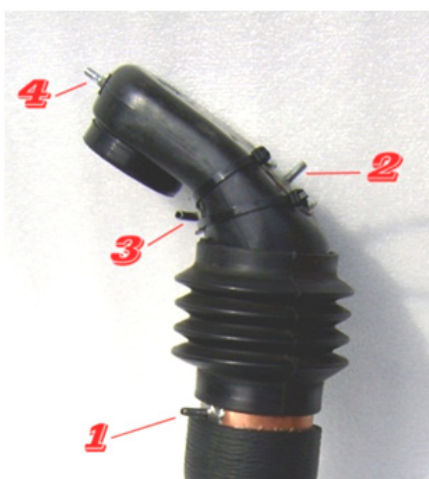

(c)

Figure 45. a, b, c.; Position and number of pressure intake ports

A number of the pressure intake ports were made downstream the air filter and measurements were made at different operating regimes for the engine installed on the stand, for different super absorbing filters designed and made by the authors. The position of the pressure intake ports on the engine intake route is illustrated in Figure 45.

Measurements were performed in no-load (idling) engine motion at various revolutions. Relative pressure values were measured on the intake route points where pressure ports 
have been mounted, as shown in Figure 45. TESTO 510 digital manometer (0-100hPa) was used. For example see [3].

Also, to simulate vehicle movement, measurements were performed in the presence of a fan positioned in front of the cooling radiator of the engine installed on the stand.

Measuring the speed of airflow from the fan to the engine radiator took place using a digital anemometer, Lutron LM - 8010 type. Engine revolution was measured with a VELLEMAN DTO $6234 \mathrm{~N}$ digital tachometer.

In addition, engine noise measurements were made for operation with different filter types, with a Lutron SL - 4012 type sound level meter.

Data were collected for the inlet system equipped with original classic air filter - OAF (Figure 46), super absorbing cylindrical air filter with internal diffuser - SAAFid (Figure 47), supliform super absorbing air filter - suSAAF (Figure 48), super absorbing filter with wide filtration range - SAAFwr (Figure 49) and for the dynamic air transfer device DATD (figure 50).

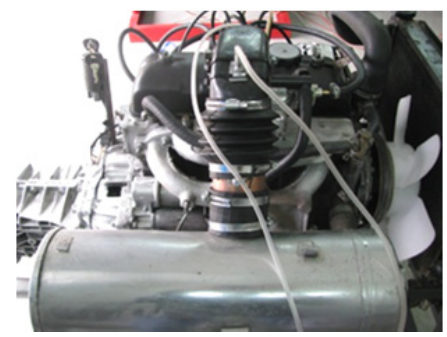

Figure 46. Original classic filter trial

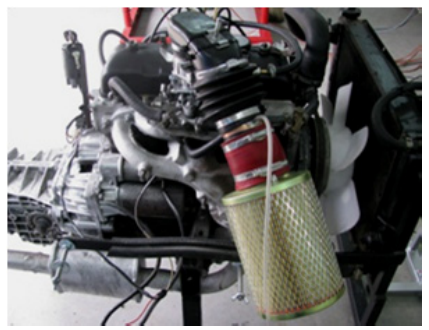

Figure 47. Super absorbing cylindrical filter with internal diffuser trial

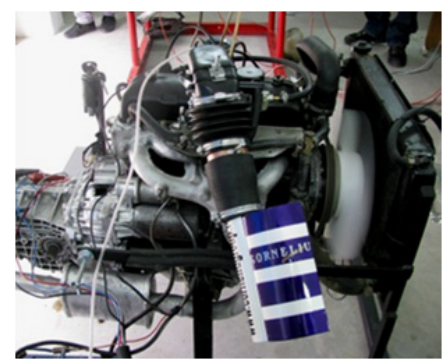

Figure 48. Supliform super absorbing filter trial 


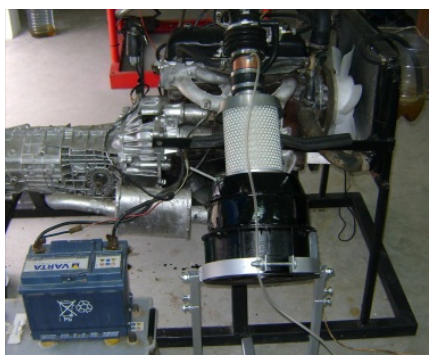

Figure 49. Super absorbing with wide filtration range trial

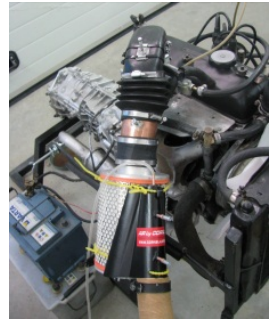

(a)

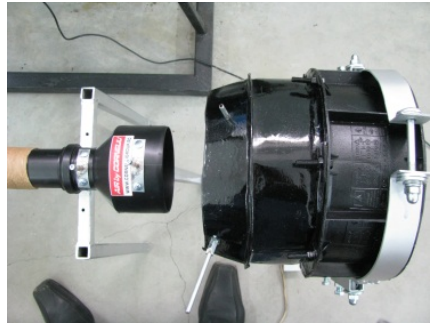

(b)

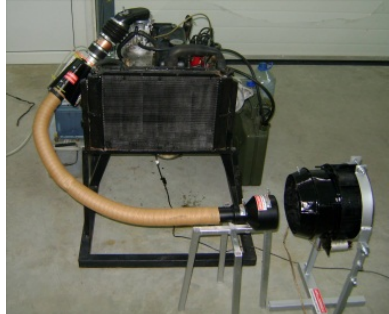

(c)

Figure 50. a, b, c: Dynamic air transfer device DATD trial

Further are presented comparative graphs of the relative pressure values recorded for each concept, for each individual pressure intake port.

Due to the presence of pressure waves generated by alternative movement of the pistons in the cylinders and the periodic opening and closing of the intake valves, pressure values fluctuate within a fairly wide range. Therefore, after stabilization of engine revolution, limit values (upper and lower) of the pressure in the ports mounted were registered and their average was calculated. These averages were used for plotting the graphs below.

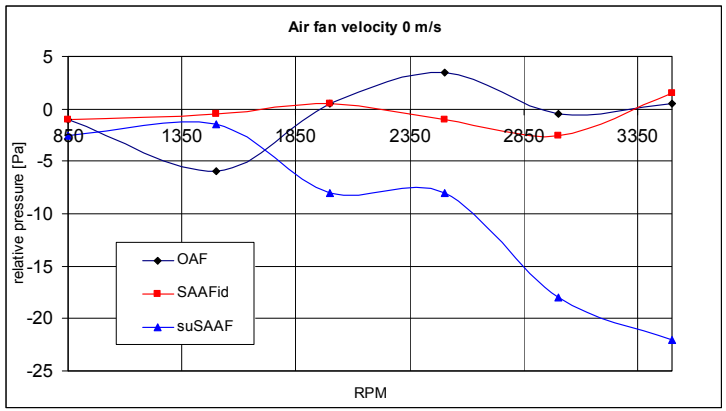

OAF - Original Air Filter, SAAFid - Super Absorbing Air Filter with internal diffuser, suSAAF - supliform Super Absorbing Air Filter

Figure 51. Values for pressure intake port 1, without vehicle movement simulation 


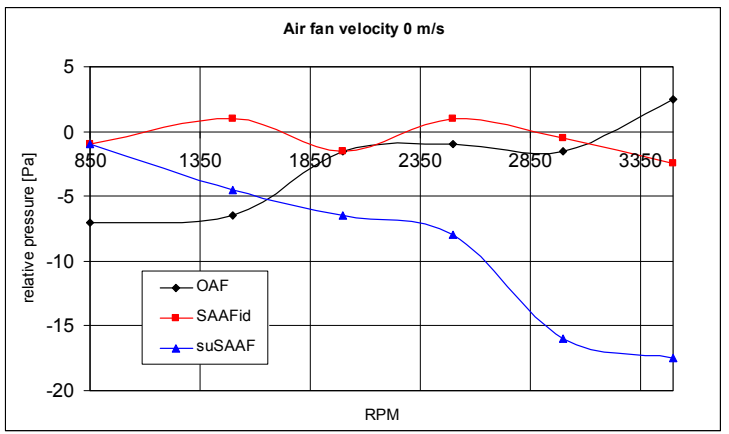

OAF - Original Air Filter, SAAFid - Super Absorbing Air Filter with internal diffuser, suSAAF - supliform Super Absorbing Air Filter

Figure 52. Values for pressure intake port 2, without vehicle movement simulation

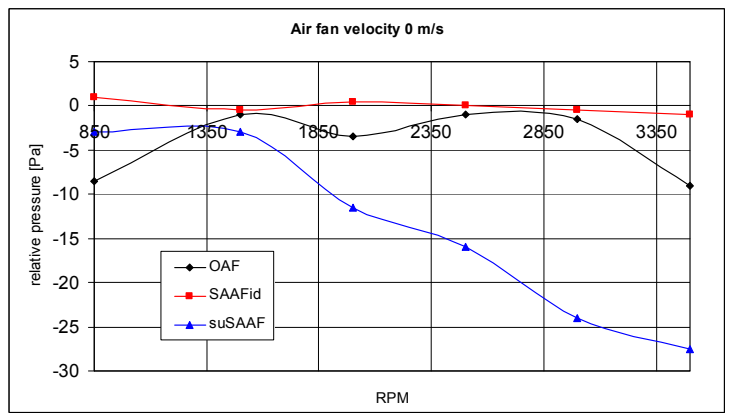

OAF - Original Air Filter, SAAFid - Super Absorbing Air Filter with internal diffuser, suSAAF - supliform Super Absorbing Air Filter

Figure 53. Values for pressure intake port 3, without vehicle movement simulation

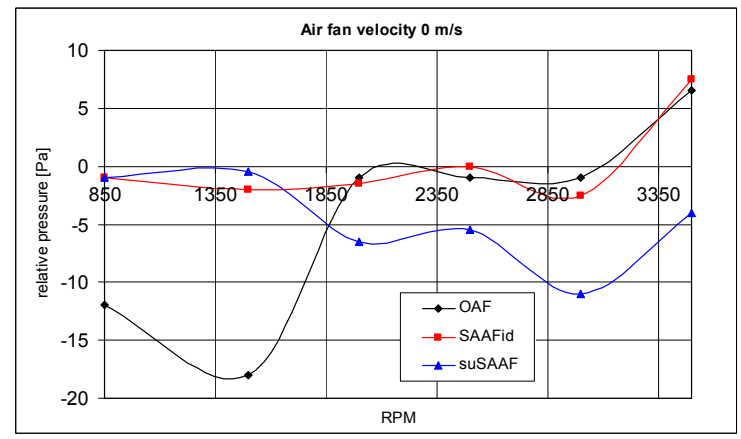

OAF - Original Air Filter, SAAFid - Super Absorbing Air Filter with internal diffuser, suSAAF - supliform Super Absorbing Air Filter

Figure 54. Values for pressure intake port 4, without vehicle movement simulation 


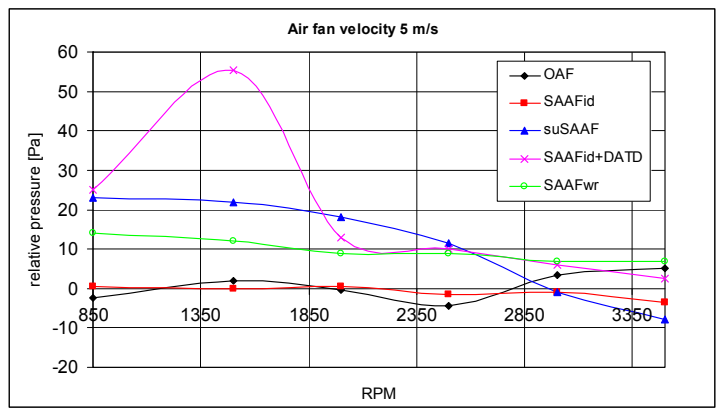

OAF - Original Air Filter, SAAFid - Super Absorbing Air Filter with internal diffuser, suSAAF - supliform Super Absorbing Air Filter, DATD - Dynamic Air Transfer Device, SAAFwr - Super Absorbing Air Filter with wide filtration range

Figure 55. Values for pressure intake port 1 , with vehicle movement simulation

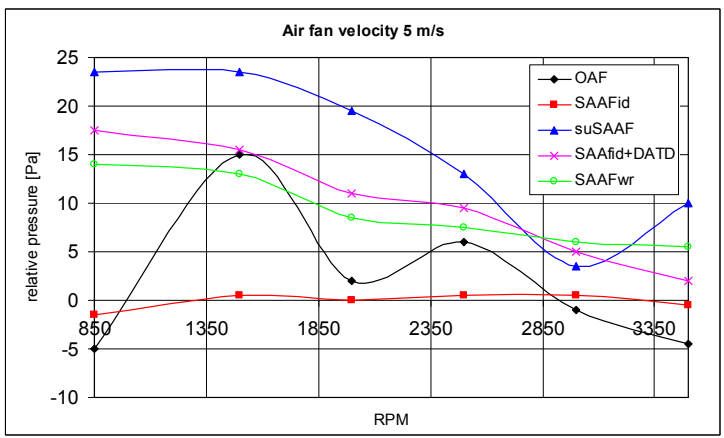

OAF - Original Air Filter, SAAFid - Super Absorbing Air Filter with internal diffuser, suSAAF - supliform Super Absorbing Air Filter, DATD - Dynamic Air Transfer Device, SAAFwr - Super Absorbing Air Filter with wide filtration range

Figure 56. Values for pressure intake port 2, with vehicle movement simulation

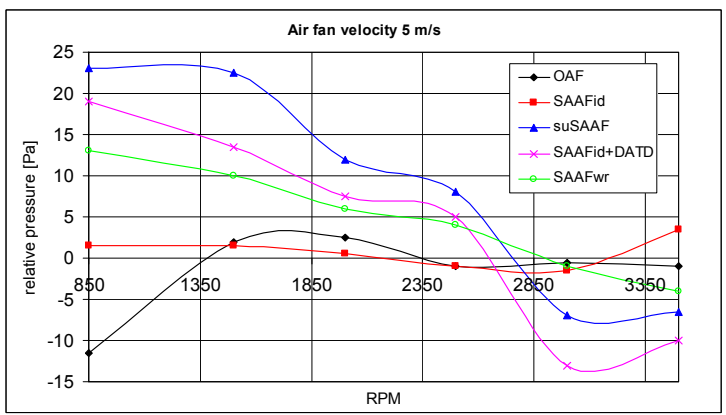

OAF - Original Air Filter, SAAFid - Super Absorbing Air Filter with internal diffuser, suSAAF - supliform Super Absorbing Air Filter, DATD - Dynamic Air Transfer Device, SAAFwr - Super Absorbing Air Filter with wide filtration range

Figure 57. Values for pressure intake port 3, with vehicle movement simulation 


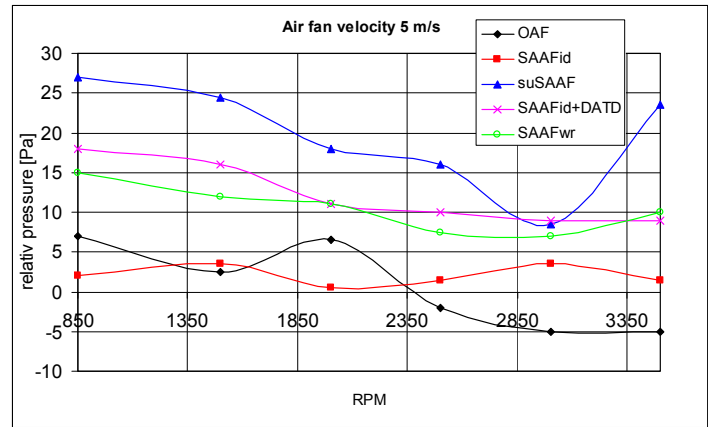

OAF - Original Air Filter, SAAFid - Super Absorbing Air Filter with internal diffuser, suSAAF - supliform Super Absorbing Air Filter, DATD - Dynamic Air Transfer Device, SAAFwr - Super Absorbing Air Filter with wide filtration range

Figure 58. Values for pressure intake port 4 , with vehicle movement simulation

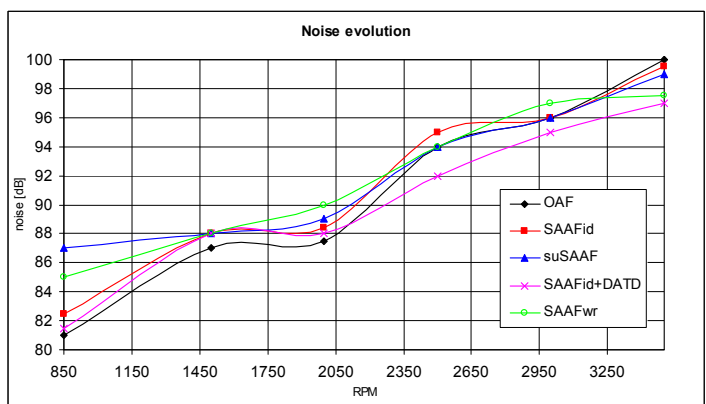

OAF - Original Air Filter, SAAFid - Super Absorbing Air Filter with internal diffuser, suSAAF - supliform Super Absorbing Air Filter, DATD - Dynamic Air Transfer Device, SAAFwr - Super Absorbing Air Filter with wide filtration range

Figure 59. Evolution of noise depending on engine revolution

The following are comparative graphs of the evolution of relative pressure on the intake route for each revolution regime, with vehicle movement simulation (air fan velocity $5 \mathrm{~m} / \mathrm{s}$ ).

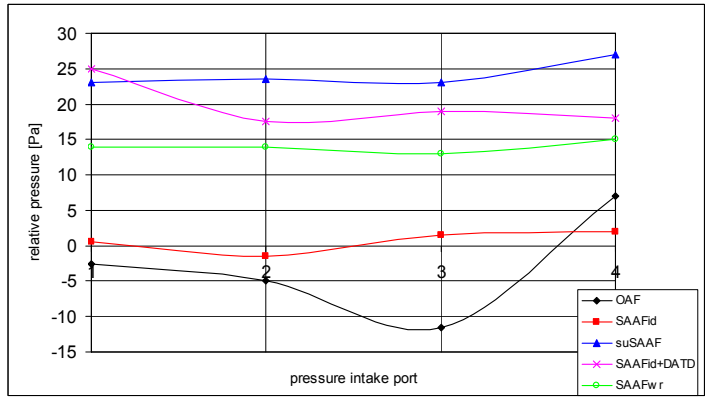

OAF - Original Air Filter, SAAFid - Super Absorbing Air Filter with internal diffuser, suSAAF - supliform Super Absorbing Air Filter, DATD - Dynamic Air Transfer Device, SAAFwr - Super Absorbing Air Filter with wide filtration range

Figure 60. Evolution of relative pressure on intake route, $800 \mathrm{RPM}$ 


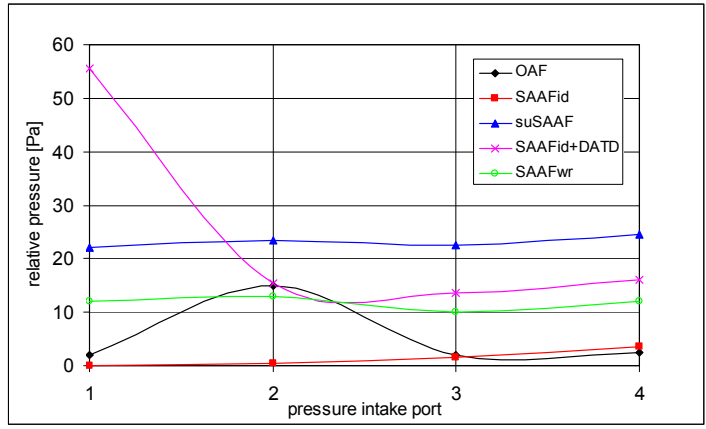

OAF - Original Air Filter, SAAFid - Super Absorbing Air Filter with internal diffuser, suSAAF - supliform Super Absorbing Air Filter, DATD - Dynamic Air Transfer Device, SAAFwr - Super Absorbing Air Filter with wide filtration range

Figure 61. Evolution of relative pressure on intake route, 1500 RPM

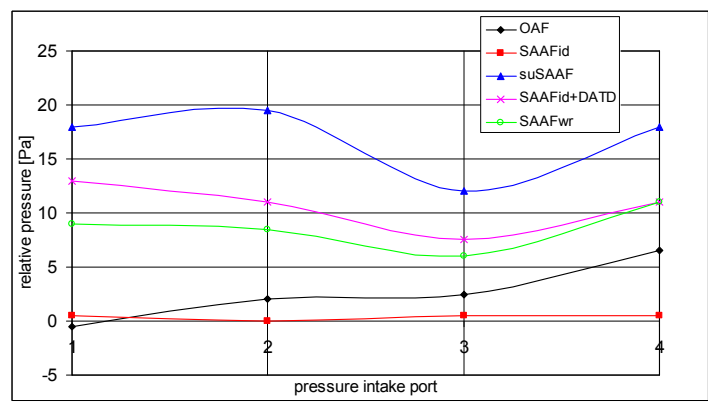

OAF - Original Air Filter, SAAFid - Super Absorbing Air Filter with internal diffuser, suSAAF - supliform Super Absorbing Air Filter, DATD - Dynamic Air Transfer Device, SAAFwr - Super Absorbing Air Filter with wide filtration range

Figure 62. Evolution of relative pressure on intake route, 2000 RPM

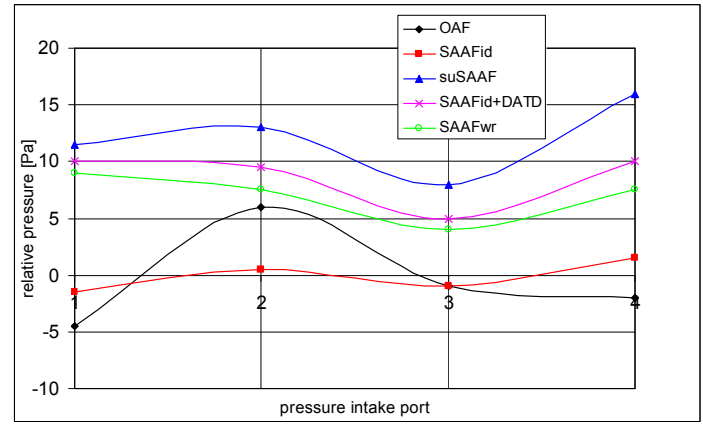

OAF - Original Air Filter, SAAFid - Super Absorbing Air Filter with internal diffuser, suSAAF - supliform Super Absorbing Air Filter, DATD - Dynamic Air Transfer Device, SAAFwr - Super Absorbing Air Filter with wide filtration range

Figure 63. Evolution of relative pressure on intake route, 2500 RPM 


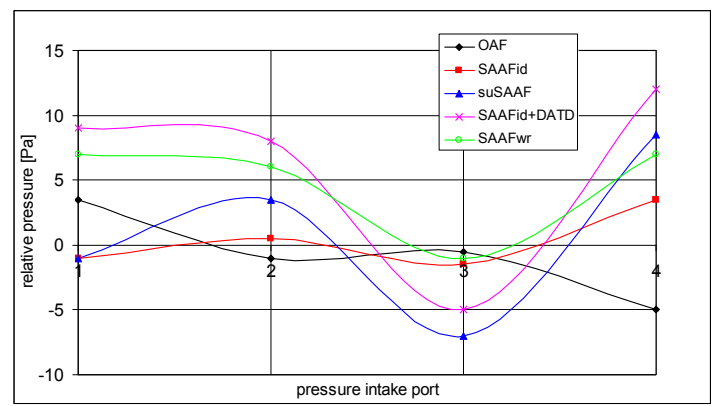

OAF - Original Air Filter, SAAFid - Super Absorbing Air Filter with internal diffuser, suSAAF - supliform Super Absorbing Air Filter, DATD - Dynamic Air Transfer Device, SAAFwr - Super Absorbing Air Filter with wide filtration range

Figure 64. Evolution of relative pressure on intake route, 3000 RPM

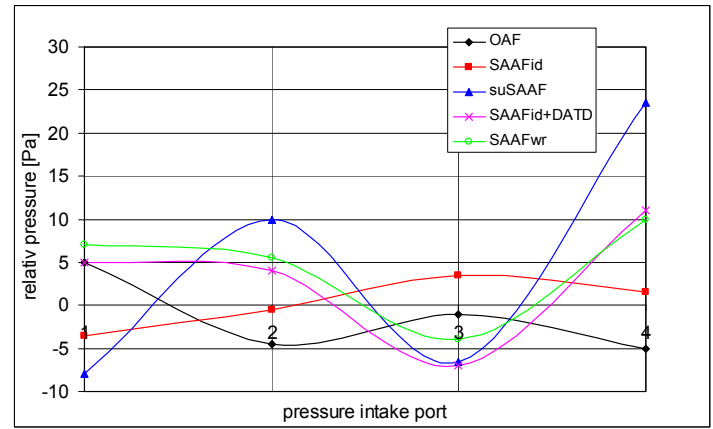

OAF - Original Air Filter, SAAFid - Super Absorbing Air Filter with internal diffuser, suSAAF - supliform Super Absorbing Air Filter, DATD - Dynamic Air Transfer Device, SAAFwr - Super Absorbing Air Filter with wide filtration range

Figure 65. Evolution of relative pressure on intake route, 3500 RPM

\section{Conclusions}

Studying the pressure evolution for each pressure intake port and at different engine revolutions (RPM), we can conclude the following [2,4]:

1. The appearance of a slight superpressure effect introduced by the super absorbing filters with internal diffuser (SAAFid) and with wide filtration range (SAAFwr), throughout the revolution range, which is beneficial to the filling process;

2. The superpressure effect is more noticeable at low revolutions, for all filter concepts and decreases with revolution increase;

3. The super absorbing filters with internal diffuser and with wide filtration range retain the superpressure effect for high revolutions;

4. The fluctuation of pressure depending on revolution is less acute in super absorbing filters with internal diffuser and with wide filtration range; 
5. Following the evolution of pressure on the intake route for different engine revolutions it is found that the filters designed have much diminished pressure fluctuation as compared to the one induced by the original classic air filter (OAF) for low revolutions. At high revolutions, the evolution of pressure is somewhat similar for all filters.

Seen as a whole, we can say that the super absorbing air filters (SAAF) together with the dynamic air transfer device (DATD) and the integrated deflector (ID) for attenuation of thermal radiation coming from the cooling radiator, lead to the following advantages:

- $\quad$ Reducing pressure losses on the air intake route in the engine cylinders, which leads to an increase in the inlet air pressure and thus to an increase in the amount of air retained in the cylinders during an engine cycle;

- Less acute heating of the air filter during engine operation, especially in summer. The low air filter temperature means less intense heating of the filtered air during engine operation, with beneficial effects on air density. Cooler air means higher density, i.e. larger amount of air retained in the engine cylinders during an engine cycle.

\section{Author details}

Sorin Rațiu1,2,* and Corneliu Birtok-Băneasă ${ }^{1,3,4}$

1"Politehnica" University of Timisoara, Romania,

${ }^{2}$ Engineering Faculty of Hunedoara, Romania,

${ }^{3}$ Mechanical Faculty of Timisoara, Romania,

${ }^{4}$ Corneliu Group, Romania

\section{References}

[1] Rațiu S, Mihon L (2008) Internal Combustion Engines for Motor Vehicles - Processes and Features, MIRTON Publishing House, Timişoara, pp. 44-47;

[2] Birtok-Băneasă C, Rațiu S (2011) Air Intake of Internal Combustion Engines - Super Absorbing Filters - Dynamic Transfer Devices, POLITEHNICA Publishing House, Timişoara, pp. 15-90;

[3] Rațiu S (2009) Internal Combustion Engines for Motor Vehicles - Processes and Features Laboratory Experiments, MIRTON Publishing House, Timişoara, pp. 40-42;

[4] Rațiu S, Birtok-Băneasă C, Alic C, Mihon L (2009) New concepts in modeling air filters for internal combustion engines, 20 $0^{\text {th }}$ International DAAAM SYMPOSIUM "Intelligent Manufacturing \& Automation: Theory, Practice \& Education", Vienna, Austria, ISSN 1726-9679

[5] www.corneliugroup.ro

${ }^{*}$ Corresponding Author 